\title{
Vedolizumab in the management of inflammatory bowel diseases: a Brazilian observational multicentric study
}

\author{
Ramir Luan PERIN¹, Aderson Omar Mourão Cintra DAMIÃO², Cristina FLORES ${ }^{3}$, Juliano Coelho LUDVIG ${ }^{4}$, \\ Daniéla Oliveira MAGR0 ${ }^{5}$, Eron Fábio MIRANDA ${ }^{1}$, Antonio Carlos de MORAES ${ }^{6}$, Rodrigo Bremer NONES ${ }^{7}$, \\ Fábio Vieira TEIXEIRA ${ }^{8}$, Marco ZERONCI0 ${ }^{9}$ and Paulo Gustavo KOTZE1
}

\section{KEY POINTS}

Summarise the established knowledge on this subject

Vedolizumab's efficacy and safety profiles were described in pivotal trials which lead to worldwide approval by regulatory agencies.

Criteria to enter pivotal trials are strict, and in clinical practice, not all patients would represent the population from clinical trials.

Real-world experience with vedolizumab from different areas from the globe demonstrated its efficacy in clinical practice, but no studies in Latin America were published to date.

What are the significant and/or new findings of this study?

This study represents the first detailed description of vedolizumab's efficacy and safety profile in Latin American patients.

Clinical remission, response and mucosal healing rates were in accordance with other real-world studies with vedolizumab.

ABSTRACT - Background - There is scarce data regarding efficacy and safety of vedolizumab in inflammatory bowel diseases in Latin America. Objective - To describe the first observational real-world experience with vedolizumab in Latin American inflammatory bowel diseases patients. Methods - Retrospective observational multicentric study of patients with Crohn's disease (CD) and ulcerative colitis (UC) who used vedolizumab at any phase of their treatment. Clinical remission and response (according to Harvey-Bradshaw index for CD and Mayo score for UC), mucosal healing, need for surgery and adverse events were evaluated. Results - A total of 90 patients were included (52 with CD and 38 with UC), the majority with previous exposure to anti-TNF agents $(88.46 \%$ in $\mathrm{CD}$ and $76.31 \%$ in UC). In CD (as observed analysis) remission rates at weeks 12,26 and 52 were $42.89 \%$ (21/49), $61.9 \%$ (26/42) and 46.15\% (12/26), respectively. In UC, remission rates at weeks 12,26 and 52 were $28.94 \%(11 / 38), 36.66 \%$ $(11 / 30)$ and $41.17 \%$ (7/17). Mucosal healing rates were $36.11 \%$ in CD and $43.4 \%$ in UC. During the study period, $7 / 52$ CD patients underwent major abdominal surgery and 4/38 UC patients needed colectomy. Conclusion - Vedolizumab was effective in induction and maintenance of clinical response and remission in CD and UC, with no new safety signs.

HEADINGS - Crohn disease. Ulcerative colitis. Inflammatory bowel diseases. Integrins. Monoclonal antibodies.

\section{INTRODUCTION}

Inflammatory bowel diseases (IBD), Crohn's disease (CD) and ulcerative colitis (UC), affect approximately 1.4 million people in the United States, about 420 thousand in Germany and even $396 / 100.000$ people across the world ${ }^{(1)}$. Medical treatment options for IBD significantly improved during the last couple of decades, especially due to the introduction of anti-tumor necrosis factor (TNF) alfa antibodies, which revolutionized patient management. Clinical response rates with anti-TNF agents range from $35 \%$ to $58 \%$ on $\mathrm{CD}$ and from $51 \%$ to $69 \%$ on $\mathrm{UC}^{(2-7)}$. However, up to $20 \%-30 \%$ of patients are primary non-responders to this type of treatment ${ }^{(8)}$. Besides that, a substantial number of patients develop secondary loss of response, requiring dose optimization ( $23 \%-46 \%$ of patients), or switching to other biologic in up to $5 \%-13 \%$ of the cases $^{(9-13)}$. Additionally, the use of these agents can be associated to possible adverse events $^{(14-16)}$. Therefore, new biological agents with alternative mechanisms of action became required.

Vedolizumab (VDZ) is an IgG humanized monoclonal antibody, that inhibits the $\alpha 4 \beta 7$ integrin, selectively blocking leukocyte trafficking from the vascular endothelium to the intestinal wall layers. Its mechanism of action depends on the specific blocking

Declared conflict of interest of all authors: Damião AOMC: Abbvie, Janssen, Takeda. Flores C: Abbvie, Janssen, Takeda. Ludvig JC: Abbvie, Janssen, Takeda and UCB. Miranda EF: Abbvie, Janssen, Takeda. Moraes AC: Merck, Abbvie, Janssen, Takeda. Teixeira FV: Abbvie, Janssen, Takeda. Zeroncio M: Ache, Abbvie, Janssen, Takeda, Pfizer. Kotze PG: Abbvie, Janssen, Takeda, Pfizer and UCB. All other authors have no conflicts of interest.

Disclosure of funding: no funding received

${ }^{1}$ Universidade Católica do Paraná, Unidade de Cirurgia Colorretal, Ambulatório de Doenças Inflamatórias Intestinais, Curitiba, PR, Brasil. ${ }^{2}$ Universidade de São Paulo (USP), Departamento de Gastroenterologia, São Paulo, SP, Brasil. ${ }^{3}$ Universidade Federal de Rio Grande do Sul (UFRGS), Hospital de Clínicas de Porto Alegre, Serviço de Gastroenterologia, Porto Alegre, RS, Brasil. Clínica ESADI, Ambulatório de Doenças Inflamatórias Intestinais, Blumenau, SC, Brasil. ${ }^{5}$ Universidade Estadual de Campinas (UNICAMP), Faculdade de Ciências Médicas, Departamento de Cirurgia, Campinas, SP, Brasil. ${ }^{6}$ Universidade Federal do Rio de Janeiro (UFRJ), Hospital Clementino Fraga Filho, Departamento de Gastroenterologia; Hospital Copa D'Or, Rio de Janeiro, RJ, Brasil. ${ }^{7}$ Hospital Nossa Senhora das Graças (HNSG), Departamento de Gastroenterologia, Curitiba, PR, Brasil. ${ }^{8}$ Clínica GastroSaúde, Ambulatório de Doenças Inflamatórias Intestinais, Marília, SP, Brasil. ${ }^{9}$ Clínica privada, Gastroenterologia, Natal, RN, Brasil.

Corresponding author: Ramir Luan Perin. Email: luanperin@gmail.com 
of the interaction between the $\alpha 4 \beta 7$ integrin heterodimer, preventing its coupling to the adenosine cell adhesion molecule of the endothelial mucosa (MAdCAM-1). Thus, it reduces the population of inflammatory cells at the intestinal mucosal level. The efficacy of VDZ in the induction and maintenance of clinical response and remission, on CD and UC patients demonstrated in pivotal studies $^{(17,18)}$. Clinical response and remission rates, in long-term follow-up, were also evidenced in long term open label studies ${ }^{(19,20)}$. Besides that, due to its intestinal selectivity, VDZ is theoretically related to lower systemic immunosuppression, and its safety profile may be favorable as compared to other monoclonal antibodies.

The patient population included in pivotal studies may not represent the daily practice of IBD, because there are usually strict inclusion criteria in main trials. Therefore, it is important to study the drug's efficacy in daily clinical practice, in order to better position VDZ in treatment algorithms in IBD. In terms of real-world data, despite several studies published in different regions of the globe, there is a lack of studies regarding the use of VDZ for IBD in Latin America ${ }^{(21,22)}$.

Within this scenario, the primary aim of this study was to analyze the rates of clinical remission in induction and maintenance therapy with VDZ in Brazilian patients with CD and UC. The secondary objectives were to analyze the rates of clinical response, endoscopic remission, adverse events and rates of abdominal surgery during therapy.

\section{METHODS}

\section{Study design}

This was a retrospective and observational study of patients with CD and UC who used VDZ at any phase of their treatment. The patients were treated at eight tertiary referral centers in the management of IBD in Brazil, during a 3-year period (May 2015 to May 2018).

\section{Inclusion and exclusion criteria}

The inclusion criteria were adult patients (over 18 years old) with CD or UC, treated with VDZ for at least 12 weeks, regardless the previous use of other biological agents, on an outpatient basis. The exclusion criteria were patients with undetermined or other colitis (microscopic, ischemic or infectious), patients with severe $\mathrm{UC}$ or CD admitted to the hospital and patients under 18 years old.

\section{Treatment and variables analyzed}

The demographic characteristics from the patients were analyzed, as sex, age at the treatment initiation, smoking status and disease duration from diagnosis to VDZ initiation. In patients with $\mathrm{CD}$, the Montreal classification was described (age at diagnosis, disease location, phenotype and presence of perianal CD) and the Harvey-Bradshaw index (HBI) was evaluated at baseline and at different time points ${ }^{(23,24)}$. In UC, disease extension (distal proctitis, left colitis, or extensive colitis) was evaluated, as well as the full Mayo score before induction and at different periods. Concomitant or previous medications were additionally analyzed in both diseases (corticosteroids, immunosuppressants and anti-TNFs).

After the induction dose of $300 \mathrm{mg}$ of VDZ at weeks 0,2 and 6 , and maintenance therapy with $300 \mathrm{mg}$ every eight weeks, the patients were evaluated at 12, 26 and 52 weeks. Dose optimization for every four weeks could be indicated according to physicians' discretion. Clinical evaluation data were checked at weeks 12, 26 and 52 by measurement of the partial Mayo score in UC and the $\mathrm{HBI}$ in CD patients, tools which are regularly used in all involved centers, to analyze remission and response. Colonoscopy was also performed to evaluate mucosal healing, at variable times, according to physicians' discretion. Primary and secondary loss of response to VDZ, discontinuation of the drug, adverse events and the need for dose optimization or switching for another biological agent were also analyzed. Abdominal surgeries and adverse events during VDZ treatment were equally checked in both diseases.

\section{Definitions}

Clinical remission (primary objective) was analyzed at weeks 12 , 26 and 52, and it was defined as a partial Mayo score $\leqslant 2$ points for $\mathrm{UC}$, or a $\mathrm{HBI} \leqslant 4$ points for $\mathrm{CD}$. Clinical response was defined as a reduction of $\geqslant 2$ points on partial Mayo score for $\mathrm{UC}$ or $\geqslant 3$ points on $\mathrm{HBI}$ for CD. Endoscopic remission was defined as endoscopic Mayo subscore of 0 for UC and a complete absence of ulcers in patients with CD. Patients were defined as primary non-responders when they didn't present any changes in the clinical picture with VDZ induction according to Physician Global Assessment (PGA). Secondary loss of response was defined according to one of the criteria below: Need for dose optimization for every four weeks, switch of biological agent, need for steroid rescue therapy or abdominal surgery during VDZ treatment.

\section{Statistical analysis}

For quantitative variables with normal distribution, mean \pm standard deviation was presented and the Student's $t$ test was used to compare two independent samples. The qualitative variables were shown as percentages, and the chi-square test was used to compare both proportions (of independent samples). The exact Fisher test was used when the total number of cases was lower than 20.

Remission, response rates and mucosal healing were evaluated in both groups (CD and UC) by the NRI (non-responder inputation) method, where the patients who were not followed until the time period were considered as failures and as observed analysis, where only patients who actually reached the studied time point were included. The data were analyzed using IBM SPSS Statistics for Windows, version 24.0 (IBM Corporation, Armonk, NY, USA). $P<0.05$ values were considered significant.

\section{Ethical considerations}

This study was approved by the ethical review board from Pontifícia Universidade Católica do Paraná (PUCPR) and all involved institutions (in september 13th, 2017), under reference number 70875317.5.0000.0020, at the ministry of health website plataforma brasil. All patients gave informed consent to use clinical information from the databases. The study protocol conforms to the ethical guidelines of the 1975 Declaration of Helsinki as reflected in a priori approval by the institution's human research committee.

\section{RESULTS}

\section{Patients characteristics}

A total of 90 patients were included (52 with CD and 38 with $\mathrm{UC})$. The baseline characteristics of the patients are described in detail in TABLE 1. As observed, CD patients mostly had ileocolic disease with inflammatory phenotype. The majority of patients had previous abdominal surgery $(30 / 52-57.69 \%)$ and were previously exposed to anti-TNF agents. Few patients (6/52-11.54\%) were naïve 
TABLE 1. Baseline characteristics from analyzed patients. Values are presented as number $(\%)$.

\begin{tabular}{|c|c|c|c|}
\hline Variable & $\begin{array}{c}\text { Crohn's } \\
\text { disease } n=52\end{array}$ & $\begin{array}{l}\text { Ulcerative } \\
\text { colitis } \mathrm{n}=38\end{array}$ & $P$-value \\
\hline $\begin{array}{l}\text { Male }-\mathrm{n}(\%) \\
\text { Female }-\mathrm{n}(\%)\end{array}$ & $\begin{array}{l}21(40.4) \\
31(59.6)\end{array}$ & $\begin{array}{l}24(63.2) \\
14(36.8)\end{array}$ & 0.03 \\
\hline Age $(\mathrm{Md} \pm \mathrm{SD})$ & $42.76 \pm 17.27$ & $40.5 \pm 15.88$ & 0.15 \\
\hline \multicolumn{4}{|l|}{ Smoking - n (\%) } \\
\hline Yes & $2(4.0)$ & $1(2.6)$ & 1.00 \\
\hline No & $50(56.0)$ & $37(97.4)$ & 0.09 \\
\hline \multicolumn{4}{|c|}{ Montreal disease allocation $-\mathrm{n}(\%)$} \\
\hline L1 (ileal) & $13(25 \%)$ & - & - \\
\hline L2 (colonic) & $14(26.92 \%)$ & - & - \\
\hline L3 (ileo-colonic) & $25(48.07 \%)$ & - & - \\
\hline E1 (proctitis) & - & $1(2.63 \%)$ & - \\
\hline E2 (left-sided colitis) & - & $16(42.10 \%)$ & - \\
\hline E3 (pancolitis) & - & $19(50 \%)$ & \\
\hline \multicolumn{4}{|c|}{ Montreal disease behavior - $\mathrm{n}(\%)$} \\
\hline B1 (inflammatory) & $26(50 \%)$ & - & - \\
\hline B2 (stricturing) & $13(25 \%)$ & - & - \\
\hline B3 (penetrating) & $13(25 \%)$ & - & - \\
\hline $\begin{array}{l}\text { Previous abdominal CD } \\
\text { surgery }-\mathrm{n}(\%)\end{array}$ & $30(57.69 \%)$ & - & - \\
\hline Ileostomy $-\mathrm{n}(\%)$ & $3(5.76 \%)$ & - & - \\
\hline $\begin{array}{l}\text { Coinduction with } \\
\text { steroids - n }(\%)\end{array}$ & $30(57.69 \%)$ & $29(76.31 \%)$ & 0.07 \\
\hline $\begin{array}{l}\text { Azathioprine/ 6-MP } \\
\text { concomitant - n (\%) }\end{array}$ & $11(21.15 \%)$ & $17(44.7 \%)$ & 0.02 \\
\hline Previous Anti-TNF - n (\%) & $46(88.46 \%)$ & $29(76.31 \%)$ & 0.21 \\
\hline 1 biological failure - n (\%) & $20(38.46 \%)$ & $21(55.26 \%)$ & 0.17 \\
\hline 2 biological failures - n (\%) & $25(48.07 \%)$ & $8(21.05 \%)$ & 0.01 \\
\hline 3 biological failures - n (\%) & $1(1.92 \%)$ & - & - \\
\hline
\end{tabular}

Chi-square test or Fisher test and Student's t test. CD: Crohn's disease.

to biological therapy. Three CD patients had ileostomies and were excluded from the efficacy analysis due to impossibility to calculate the HBI, despite included in the safety analysis. UC patients were predominantly men. Most of the patients showed extensive colonic involvement $(50 \%, 19 / 38$ with pancolitis and $42.10 \%, 16 / 38$ with left-sided colitis). The average time of follow-up was $11.26 \pm 4.41$

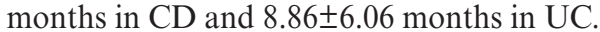

\section{Crohn's disease}

Clinical remission findings are summarized in FIGURE 1. In as observed analysis, remission rates at weeks 12,26 and 52 were $42.89 \%(21 / 49), 61.9 \%(26 / 42)$ and $46.15 \%(12 / 26)$, respectively. In NRI analysis, remission rates on the corresponding time periods were $42.85 \%$ (21/49), 53.06\% (26/49) and 24.48\% (12/49), respectively. Clinical response findings in CD are summarized in FIGURE 2.

Colonoscopies were performed during follow-up to evaluate endoscopic remission in 36 of the 52 patients, with an average time of $7.66 \pm 2.49(3-12)$ months. Mucosal healing was identified in $36.11 \%(13 / 36)$ of the cases.

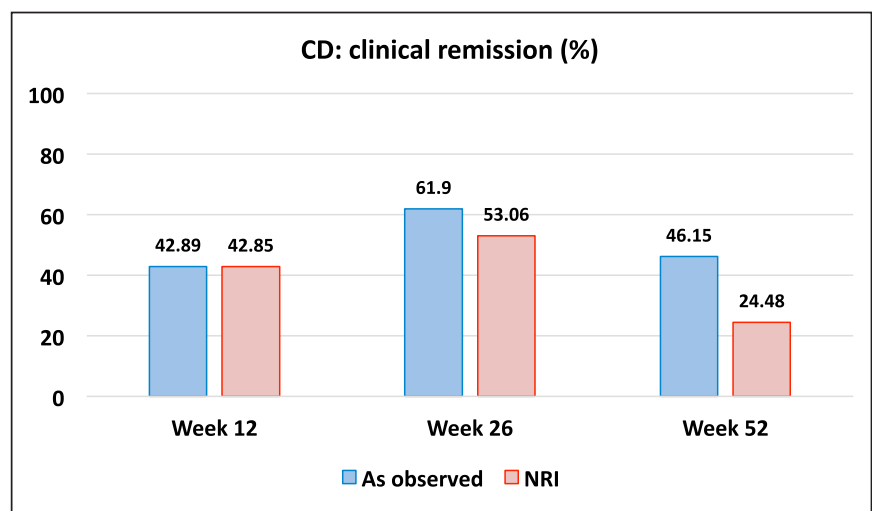

FIGURE 1. Clinical remission in Crohn's disease (CD), as observed and NRI (non-responder inputation) analyses.

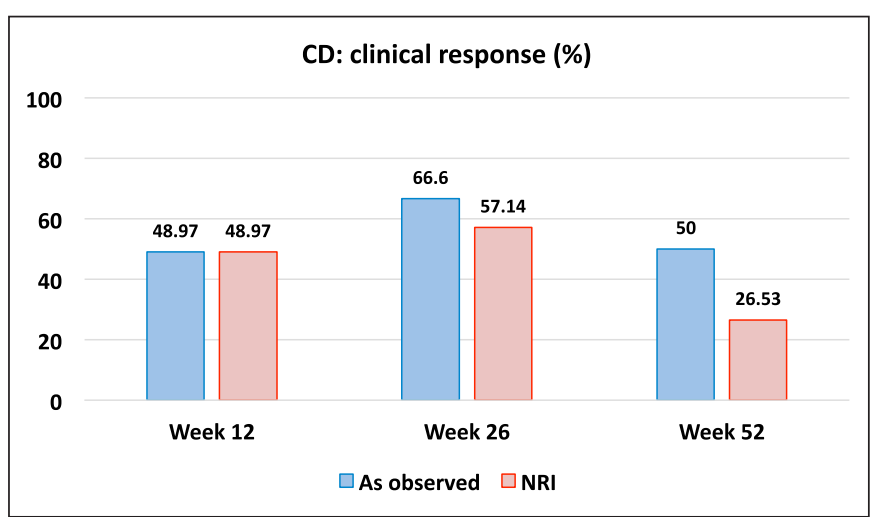

FIGURE 2. Clinical response in Crohn's disease (CD), as observed and NRI (non-responder inputation) analyses.

Thirteen patients were considered primary non-responders $(25 \%)$, while secondary loss of response was observed in 25 of the 52 patients. Dose optimization of $300 \mathrm{mg}$ every four weeks was observed in $38.46 \%(20 / 52)$ of patients, while $48.07 \%(25 / 52)$ switched biological agents (20 patients to ustekinumab, four to infliximab and one to certolizumab pegol). During the study period, seven patients were submitted to CD-related major abdominal surgery. All patients switched medication after optimization for every four weeks. Patients submitted to surgery had already or optimized or switched medication previously.

\section{Ulcerative colitis}

Clinical remission findings are summarized in FIGURE 3. In as oserved analysis, remission rates at weeks 12, 26 and 52 were $28.94 \%$ (11/38), 36.66\% (11/30) and 41.17\% (7/17), respectively. In NRI analysis, remission rates in the corresponding time periods were $28.94 \%$ (11/38), 28.94\% (11/38) and 18.42\% (7/38), respectively. Clinical response findings in UC are described in detil in FIGURE 4.

Colonoscopies were performed during follow-up in 30 of the 38 patients, with an average time of $7.5 \pm 3.23$ (3-20) months, with mucosal healing observed in $43.40 \%$ (13/30) of patients.

Six patients were considered primary non-responders $(15 \%)$. Secondary loss of response was observed in 19 of the 38 patients. Dose optimization of $300 \mathrm{mg}$ every four weeks was used in $50 \%$ (19/38) of patients, while $13.15 \%$ (5/38) switched to another biological or small molecule (one to adalimumab, one to infliximab, one 


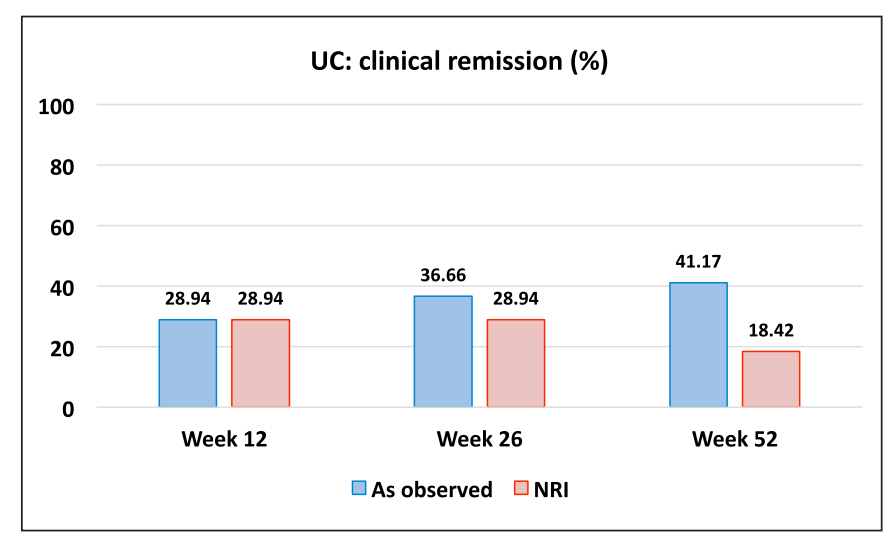

FIGURE 3. Clinical remission in ulcerative colitis (UC), as observed and NRI (non-responder inputation) analyses.

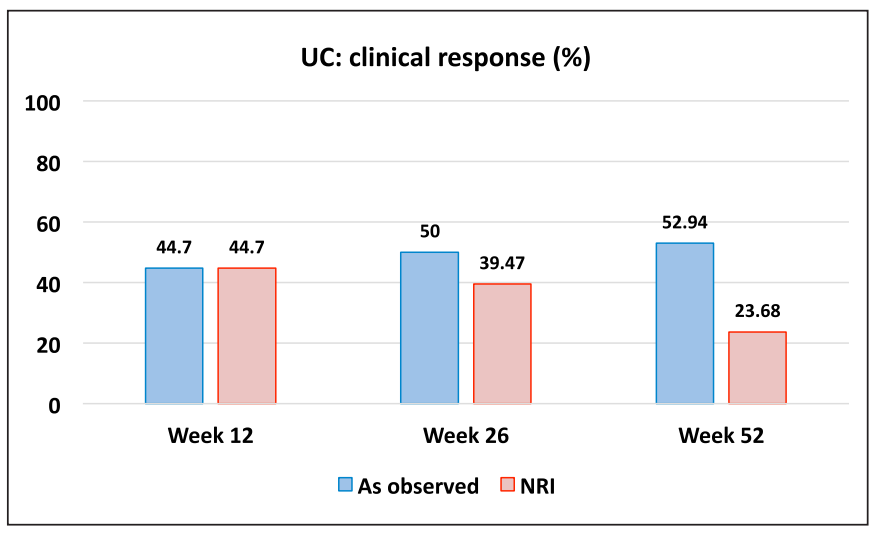

FIGURE 4. Clinical response in ulcerative colitis (UC), as observed and NRI (non-responder inputation) analyses.

to ustekinumab and two to tofacitinib). During the study period, four colectomies were performed (two total colectomies with end ileostomy, one total colectomy with ileorectal anastomosis and one restorative proctocolectomy with ileal pouch).

TABLE 2 demonstrates the comparative analysis of the efficacy results between CD and UC. At week 52, there were no differences in clinical remission rates between both diseases (primary objective of the study). However, a higher efficacy signal was observed in terms of clinical remission at week 26 in CD (both as observed and NRI analyses), and higher clinical response rates in CD in NRI analysis at weeks 26 and 52

\section{Safety}

A summary of the adverse events (AE) observed is described in detail in TABLE 3. In CD, AE were observed in $36.57 \%(17 / 52)$ of patients, the most common being upper respiratory tract infections. Two patients had nausea after infusions and two had infusion reactions. Perianal abscesses were observed in two patients and acute gastroenteritis in other two. One patient developed myelodysplasia and one patient had severe arthralgia after infusions, which lead to treatment interruption. One patient died during therapy, due to abdominal sepsis not related to CD.

In UC, AE were observed in $23.68 \%(9 / 38)$ of patients, and the most common event was upper respiratory tract infections as well (four cases). Infection due to clostridium difficille occurred in three patients. There was one urinary tract infection and one acute gastroenteritis. One patient died during follow-up due to undetermined sepsis.

\section{DISCUSSION}

Medical therapy with different mechanisms of action (apart from TNF inhibition) may be essential in the management of IBD, since some patients may have different inflammatory expression, not only related to TNF-alfa but also expressed by other proinflammatory cytokines. Real life data are important to position new therapeutic agents, since the majority of our patients do not fulfill criteria to enter randomized clinical trials, and findings from

TABLE 3. Adverse events observed in the study population.

\begin{tabular}{lccc}
\hline & $\begin{array}{c}\text { Crohn's } \\
\text { disease }(\mathbf{n}=52) \\
(\%)\end{array}$ & $\begin{array}{c}\text { Ulcerative } \\
\text { colitis }(\mathbf{n}=38) \\
(\%)\end{array}$ & $\boldsymbol{P}$ value \\
\hline Perianal abscess & $3(5.8)$ & $4(10.5)$ & 0.04 \\
Acute gastroenteritis & $2(3.8)$ & 0 & - \\
Infusion reaction & $2(3.8)$ & $1(2.6)$ & 1.00 \\
Sinusitis & $2(3.8)$ & 0 & - \\
Nausea after infusion & $2(3.8)$ & 0 & - \\
Abdominal sepsis & $1(1.9)$ & $1(2.6)$ & - \\
Bronchopneumonia & $1(1.9)$ & 0 & - \\
Myelodysplasia & $1(1.9)$ & 0 & - \\
Arthralgias & $1(1.9)$ & 0 & - \\
Urinary tract infections & 0 & $1(2.6)$ & - \\
Infection by & 0 & $3(7.9)$ & - \\
Clostridium difficille & $1(1.9)$ & $1(2.6)$ & 1.00 \\
Death & & & \\
\hline
\end{tabular}

Values are presented as number (\%). Chi-square test or Fisher test and Student's t test.

TABLE 2. Comparative analysis between CD and UC in clinical remission and clinical response, at weeks 26 and 52.

\begin{tabular}{|c|c|c|c|c|c|c|}
\hline & $\begin{array}{c}\mathrm{CD} \text { as observed } \\
(\%)\end{array}$ & $\begin{array}{c}\mathrm{UC} \text { as observed } \\
(\%)\end{array}$ & $P$ value & CD NRI (\%) & UC NRI (\%) & $P$ value \\
\hline Remission week 26 & 61.90 & 36.66 & 0.01 & 50.0 & 28.94 & $0.02 *$ \\
\hline Remission week 52 & 46.15 & 41.17 & 0.37 & 23.07 & 18.42 & 0.28 \\
\hline Response week 26 & 66.6 & 50 & 0.10 & 53.84 & 39.47 & $<0.001 * *$ \\
\hline Response week 52 & 50 & 52.94 & 0.54 & 25 & 23.68 & $0.03^{*}$ \\
\hline
\end{tabular}

Chi-square test or Fisher test. $* P<0.05 ; * * P<0.001$. CD: Crohn's disease; UC: ulcerative colitis. 
the pivotal studies may not represent efficacy observed in daily practice. In this real-life retrospective study, the efficacy and safety of VDZ for the treatment of CD and UC in Latin American patients is presented for the first time. Remission and response rates were consistent to previously published results from other observational cohorts from different parts of the world.

Schreiber et al., in a meta-analysis which included several real life studies, described a clinical response rate in $\mathrm{CD}$ of approximately $40 \%(29 \%-52 \%)$ and clinical remission of $30 \%(20 \%-42 \%)$, after 52 weeks ${ }^{(25)}$. In UC, the same authors described pooled clinical response rates of approximately $52 \%(37 \%-56 \%)$. The results from our study in both diseases were similar to the ones described in this meta-analysis, which included studies with a similar methodology than ours. In a sub-analysis, the authors highlighted better results in patients who were not previously exposed to other biological agents. In our study, there was a low number of patients naïve to previous biologics, six $(11.54 \%)$ in CD and nine (23.69\%) in UC. For this reason, a comparison regarding the status of previous exposure to biologics could not be made, and more specific studies in naïve patients are warranted in.

Our study presented clinical remission and response rates at week 52 of $24.48 \%$ and $26.53 \%$ for CD, and $18.42 \%$ and $23.68 \%$ for UC, respectively (NRI analysis). The results in CD were similar to the ones described by Kotze et al. in the largest single center experience with VDZ in the real-life setting published to date ${ }^{(22)}$. On the other hand, our efficacy results in UC were worse than the ones described in the same study. A possible reason for this is the inclusion of a higher number of naive UC patients in the Calgary cohort (circa 50\%), which corroborates to better results comparing to ours. Kopylov et al., in the only multicentric study with VDZ exclusively performed in naïve patients, presented remission and response rates in $\mathrm{CD}$ of $68.8 \%$ and $77.1 \%$, respectively ${ }^{(26)}$. The remission and response rates in UC, in the same study, were $67 \%$ and $76.7 \%$, respectively. Theses findings showed that the efficacy of VDZ in naïve patients is higher than in patients with previous exposure to anti-TNF agents. These concepts, described since pivotal studies, are observed in different drugs in the IBD field. More studies with VDZ in naïve patients are needed.

In the aforementioned meta-analysis, mucosal healing rates varied between 6 and $53 \%$ in CD patients, after 12 months of follow-up ${ }^{(25)}$. Similar rates were found in our study $(36.11 \%$ after an average time of colonoscopy of 7.66 months). In UC, mucosal healing rates in the same meta-analysis varied between 33 and $77 \%$, in the same follow-up. Our study described mucosal healing in $43.4 \%$ of UC patients in an average time of 7.5 months of colonoscopy. Even though the mucosal healing rates in the present study are similar to what is observed in the literature, one should note that our definition was more rigid than the majority of studies (complete absence of ulcers in CD and endoscopic Mayo subscore of 0 in UC).

In the present study, the safety profile of VDZ was consistent with the findings of most pivotal studies and safety sub-analysis with the drug (27). The upper respiratory tract infections were the most prevalent AEs. We also observed rare infusion reactions (only two cases). Two deaths were observed (one in UC and one in CD) due abdominal sepsis which were unrelated to IBD. Only one case of myelodysplasia was reported. No malignancy was observed. Probably with a higher number of patient and longer follow-up, more AEs could be captured.

In the current analysis, when comparing the efficacy of VDZ between $\mathrm{CD}$ and $\mathrm{UC}$, a higher clinical response rate in $\mathrm{CD}$ at NRI analysis at weeks 26 and 52 was observed. However, similar remission rates at week 52 were observed in both diseases, what is in accordance with most studies from the literature ${ }^{(26)}$. The differences found in clinical response comparison between the diseases are probably related to methodological drawbacks of our study, according to the definitions that were used.

Our study is associated with some limitations that must be analyzed before final interpretation of its results. First, this is a retrospective multicentric study, which involves information from electronic medical records, what introduces the possibility of bias in data collection. The selection bias is also highlighted, once the included population was reduced and most of the patients were refractory to multiple previous treatments (the majority presented previous exposure to one or more anti-TNFs). Although most of the practices from the involved centers follow the ECCO guidelines ${ }^{(28,29)}$, different physicians were involved in patient care, with certain variability in clinical practice, including the follow-up time, intervals between appointments and endoscopic tests. This is a limitation inherent to the methodology of observational studies. The reduction of this possible bias was based on the precise definitions of clinically relevant results, which empower our results, with a more precise description of what is seen in daily clinical practice. Despite these limitations, our study represents to date the first detailed experience with VDZ for the management of IBD in Latinamerican patients.

\section{CONCLUSION}

In this multicentric observational study, VDZ proved to be effective in induction and maintenance of clinical response and remission in $\mathrm{CD}$ and $\mathrm{UC}$, in a highly refractory population. The safety profile described was in accordance with previous data, with no new safety signs. This is the first detailed experience with VDZ in Latin American patients. Studies demonstrating the efficacy of VDZ in patients without previous exposure to biological agents are warranted.

\section{Authors' contribution}

Perin RL and Kotze PG contributed to study conception and design; Perin RL, Damiao AOMC, Flores C, Ludvig JC, Miranda EF, Moraes AC, Nones RB, Teixeira FV, Zeroncio M and Kotze PG contributed to data collection and interpretation; Magro DO contributed with data analysis. Perin RL, Magro DO and Kotze PG contributed to writing of the article; all authors contributed to editing, reviewing and final approval of the article.

\section{Orcid}

Ramir Luan Perin. Orcid: 0000-0002-8586-4611.

Aderson Omar Mourão Cintra Damião. Orcid: 0000-00017584-7351.

Cristina Flores. Orcid: 0000-0003-1623-4525.

Juliano Coelho Ludvig. Orcid: 0000-0002-8277-6958.

Daniéla Oliveira Magro. Orcid: 0000-0002-8180-6254.

Eron Fábio Miranda. Orcid: 0000-0003-4011-5112.

Antonio Carlos de Moraes. Orcid: 0000-0002-5533-5401.

Rodrigo Bremer Nones. Orcid: 0000-0002-6256-2629.

Fábio Vieira Teixeira. Orcid: 0000-0002-8915-7279.

Marco Zeroncio. Orcid: 0000-0002-1006-1101.

Paulo Gustavo Kotze. Orcid: 0000-0002-2053-5315. 
Perin RL, Damião AOMC, Flores C, Ludvig JC, Magro DO, Miranda EF, Moraes AC, Nones RB, Teixeira FV, Zeroncio M, Kotze PG. Vedolizumabe no manejo das doenças inflamatórias intestinais: um estudo multicentrico observacional brasileiro. Arq Gastroenterol. 2019;56(3):312-7.

RESUMO - Contexto - Há escassez de dados sobre a eficácia e segurança do vedolizumabe nas doenças inflamatórias intestinais na América Latina. Objetivo - Descrever a primeira experiência observacional de mundo real com vedolizumabe em pacientes latino-americanos com doenças inflamatórias intestinais. Métodos - Estudo retrospectivo multicêntrico observacional de pacientes com doença de Crohn (DC) e retocolite ulcerativa inespecífica (RCUI) que utilizaram vedolizumabe em qualquer fase de seu tratamento. Foram avaliadas a remissão e resposta clínicas (de acordo com o índice de Harvey-Bradshaw para DC e escore de Mayo para RCUI), cicatrização da mucosa, necessidade de cirurgia e eventos adversos. Resultados - Foram incluídos 90 pacientes (52 com DC e 38 com RCUI), a maioria com exposição prévia a agentes anti-TNF (88,46\% na DC e 76,31\% na RCUI). Na DC (em análise conforme observado), as taxas de remissão nas semanas 12, 26 e 52 foram 42,89\% (21/49), 61,9\% (26/42) e 46,15\% (12/26), respectivamente. Na RCUI, as taxas de remissão nas semanas 12, 26 e 52 foram de 28,94\% (11/38), 36,66\% (11/30) e 41,17\% (7/17). As taxas de cicatrização da mucosa foram $36,11 \%$ na DC e $43,4 \%$ na RCUI. Durante o período do estudo, $7 / 52$ pacientes com DC foram submetidos a cirurgia abdominal maior e $4 / 38$ pacientes com RCUI necessitaram de colectomia. Conclusão - O vedolizumabe foi eficaz na indução e manutenção da resposta e remissão clínicas em população refratária na DC e RCUI, com perfil de segurança favorável.

DESCRITORES - Doença de Crohn. Colite ulcerativa. Doença inflamatória intestinal. Integrinas. Anticorpos monoclonais.

\section{REFERENCES}

1. Lakatos PL. Recent trends in the epidemiology of inflammatory bowel diseases: up or down? World J Gastroenterol. 2006;12:6102-8.

2. Hanauer SB, Feagan BG, Lichtenstein GR, et al. Maintenance infliximab for Crohn's disease: the ACCENT I randomised trial. Lancet. 2002;359:1541-9.

3. Rutgeerts P, Sandborn WJ, Feagan BG, Reinisch W, Olson A, Johanns J, et al. Infliximab for induction and maintenance therapy for ulcerative colitis. $\mathrm{N} \mathrm{Engl}$ J Med. 2005;353:2462-76.

4. Sandborn WJ, Feagan BG, Stoinov S, Honiball PJ, Rutgeerts P, Mason D, et al. Certolizumab pegol for the treatment of Crohn's disease. N Engl J Med. 2007;357:228-38.

5. Colombel JF, Sandborn WJ, Rutgeerts P, Enns R, Hanauer SB, Panaccione R, et al. Adalimumab for maintenance of clinical response and remission in patients with Crohn's disease: the CHARM trial. Gastroenterology. 2007;132:52-65.

6. Sandborn WJ, van Assche G, Reinisch W, Colombel JF, D'Haens G, Wolf DC, et al. Adalimumab induces and maintains clinical remission in patients with moderate-to-severe ulcerative colitis. Gastroenterology. 2012;142:257-65e1-3.

7. Sandborn WJ, Feagan BG, Marano C, Zhang H, Strauss R, Johanns J, et al. Subcutaneous golimumab induces clinical response and remission in patients with moderate-to-severe ulcerative colitis. Gastroenterology. 2014;146:85-95.

8. Yanai H, Hanauer SB. Assessing response and loss of response to biological therapies in IBD. Am J Gastroenterol. 2011;106:685-98.

9. Gisbert JP, Panes J. Loss of response and requirement of infliximab dose intensification in Crohn's disease: a review. Am J Gastroenterol. 2009;104:760-7.

10. Allez M, Karmiris K, Louis E, Van Assche G, Ben-Horin S, Klein A, et al. Report of the ECCO pathogenesis workshop on anti-TNF therapy failures in inflammatory bowel diseases: definitions, frequency and pharmacological aspects. J Crohns Colitis. 2010;4:355-66.

11. Ben-Horin S. Loss of response to antitumor necrosis factors: what is the next step? Dig Dis. 2014;32:384-8.

12. Billioud V, Sandborn WJ, Peyrin- Biroulet L. Loss of response and need for adalimumab dose intensification in Crohn's disease: a systematic review. Am J Gastroenterol. 2011;106:674-84.

13. Roda G, Jharap B, Neeraj N, Colombel JF. Loss of response to anti-TNFs: definition, epidemiology, and management. Clin Transl Gastroenterol. 2016;7:e135.

14. Dulai PS, Siegel CA. The risk of malignancy associated with the use of biological agents in patients with infl ammatory bowel disease. Gastroenterol Clin North Am. 2014;43:525-41.

15. Dulai PS, Thompson KD, Blunt HB, Dubinsky MC, Siegel CA. Risks of serious infection or lymphoma with anti-tumor necrosis factor therapy for pediatric infl ammatory boweldisease: a systematic review. Clin Gastroenterol Hepatol. 2014;12:1443-51.

16. Dulai PS, Siegel CA, Colombel JF, Sandborn WJ, Peyrin-Biroulet L. Systematic review: monotherapy with antitumour necrosis factor alpha agents versus combination therapy with an immunosuppressive for IBD. Gut. 2014;63:1843-53.
17. Sandborn WJ, Feagan BG, Rutgeerts P, Hanauer S, Colombel JF, Sands BE, et al. Vedolizumab as induction and maintenance therapy for Crohn's disease. N Engl J Med. 2013;369:711-721.

18. Feagan BG, Rutgeerts P, Sands BE, Hanauer S, Colombel JF, Sandborn WJ, et al. Vedolizumab as induction and maintenance therapy for ulcerative colitis. $\mathrm{N}$ Engl J Med. 2013;369:699-710.

19. Vermeire S, Loftus EV Jr, Colombel JF, Feagan BG, Sandborn WJ, Sands BE, et al. Long-term efficacy of vedolizumab for Crohn's disease. J Crohns Colitis. 2017;11:412-24

20. Loftus Jr EV, Colombel JF, Feagan BG, Vermeire S, Sandborn WJ, Sands BE, et al. Long-term efficacy of vedolizumab for ulcerative colitis. J Crohns Colitis. 2017;11:400-11.

21. Dulai PS, Singh S, Jiang X, Peerani F, Narula N, Chaudrey K, et al. The real-world effectiveness and safety of vedolizumab for moderate-severe Crohn's disease: results from the US VICTORY consortium. Am J Gastroenterol. 2016;111:1147-55.

22. Kotze PG, Ma C, Almutairdi A, Al-Darmaki A, Devlin SM, Kaplan GG, et al. Real-world clinical, endoscopic and radiographic efficacy of vedolizumab for the treatment of inflammatory bowel disease. Aliment Pharmacol Ther. 2018; 48:626-37.

23. Silverberg M, Satsangi J, Ahmad T, Arnott, I, Bernstein CN, Brant SR, et al. Toward an integrated clinical, molecular and 339 serological classification of inflammatory bowel disease: report of a Working Party of the 2005 Montreal World Congress of Gastroenterology. Can J Gastroenterol. 2005;19 (Suppl A): 5-36A.

24. Harvey RF, Bradshaw JM. A simple index of Crohn's-disease activity. Lancet. 1980;315:514.

25. Schreiber S, Dignass A, Peyrin-Biroulet L, Hather G, Demuth D, Mosli M, et al. Systematic review with meta-analysis: real-world effectiveness and safety of vedolizumab in patients with inflammatory bowel disease. J Gastroenterol. 2018;53:1048-64.

26. Kopylov U, Verstock B, Biedermann L, Sebastian S, Pugliese D, Sonnenberg E, et al. Effectiveness and safety of vedolizumab in anti-TNF-naïve patients with inflammatory bowel disease-a multicenter retrospective European study. Inflamm. Bowel Dis. 2018;24:2442-51.

27. Colombel JF, Sands BE, Rutgeerts P, Sandborn W, Danese S, D'Haens G, et al. The safety of vedolizumab for ulcerative colitis and Crohn's disease. Gut. 2017;66:839-51

28. Gomollón F, Dignass A, Annese V, Tilg H, Van Assche G, Lindsay JO, et al. 3rd European evidence-based consensus on the diagnosis and management of Crohn's disease 2016: Part 1: Diagnosis and medical management. J Crohns Colitis. 2016;11:3-25.

29. Harbord M, Eliakim R, Bettenworth D, Karmiris K, Katsanos K, Kopylov U, et al. Third European Evidence- based Consensus on Diagnosis and Management of Ulcerative Colitis. Part 2: Current Management. J Crohns Colitis. 2017;11:1-24. 